\title{
A EXPERIÊNCIA DO FORA EM DELEUZE: O VIRTUAL TECNOLÓGICO E A VIDEOARTE
}

\author{
THE EXPERIENCE OF OUTSIDE IN DELEUZE: \\ THE TECHNOLOGICAL VIRTUAL AND THE VIDEO ART
}

\author{
Hugo Souza Garcia Ramos ${ }^{1}$ \\ Geide Rosa Coelho ${ }^{2}$
}

\begin{abstract}
Resumo: Este artigo discute a experiência do fora por meio da videoarte. Isso implica compreender que a arte do vídeo pode ser um "veículo" potente para acionar devires da subjetivação que modifica os modos de experimentação de si e do mundo. Para tanto, é abordada as temáticas do virtual e da imagem-tempo a partir do pensamento de Deleuze $(1987 ; 1988 ; 1990)$. Além disso, foi realizada uma análise dos territórios sensíveis da obra videográfica Mannequin Death (2016) de John Miller e Richard Hoeck. Concluímos, ao final, que devido as imagens de uma videoarte serem regidas sob o signo do inacabamento - uma obra-processo em que a plasticidade ganha lugar, que se instaura a possibilidade para transitar por uma experiência fora do sujeito nas dimensões do virtual. O que ocorre é um outro agenciamento com espectador em que há múltiplas produções de sentidos e linguagens sem a pretensão de estabelecer sistemas de representação.
\end{abstract}

Palavras-chave: Videoarte; subjetivação; virtual.

\begin{abstract}
This article aims to problematize the outside experience through video art. This implies understanding that the art of video can be a powerful vehicle to trigger becoming of the subjectivation that changes the ways of experiencing oneself and the world. For that, the themes of the virtual and the image-time are approached based on Deleuze's thought $(1987 ; 1988 ; 1990)$. In addition, an analysis of the videographic work Mannequin Death (2016) by John Miller and Richard Hoeck. We conclude, at the end, that the fact that the images of a video art are governed under the sign of unfinished - a work-process in which plasticity takes place, which establishes the possibility to move through an experience outside the subject in dimensions of the virtual. What happens is another agency with a spectator in which there are multiple productions of meanings and languages without the intention of establishing representation systems.
\end{abstract}

Keywords: Videoart; subjectivity; virtual.

\section{Introdução}

A videoarte surge na década de 1960, como uma estética da contracultura criando novos conceitos e formas que provocaram deslocamentos e desconstruções nos modos de se relacionar com as imagens (COHN, 2017). De forma sintética, o que ocorreu foi uma busca do deslocamento da arte como representação para religar à vida.

Os sujeitos que antes eram consumidores de imagens são convidados e provocados a participarem, construindo e inventando sentidos em relação à obra. E destacamos que isso não tem nada a ver com "explicar" ou "interpretar" as imagens. O que existe é uma coprodução em que o espectador é chamado a intervir diretamente na atualização de signos, e nesse movimento, tornar-se outro, diferindo de si mesmo e também da sua relação com o mundo. A criação, então, não se limita mais ao momento da concepção da obra pelo artista.

\footnotetext{
${ }^{1}$ Universidade Federal do Espírito Santo, ES, Brasil.

${ }^{2}$ Universidade Federal do Espírito Santo, ES, Brasil.
} 
A arte do vídeo pode ser um "veículo" potente para acionar devires da subjetivação. Para compreendermos essa proposição, abordaremos, neste texto, as temáticas do virtual e da imagem-tempo a partir do pensamento de Deleuze $(1987 ; 1988 ; 1990)$. Além disso, trazemos juntamente as contribuições de Suely Rolnik (2002; 2018), principalmente, para nos ajudar na análise da obra Mannequin Death. Compreendemos na companhia destes autores que a produção imagética nos provoca ver e pensar para além das representações e do instituído, uma vez que nos remete a perceber e captar as forças do vivo que reverberam em nossos corpos. Dessa forma, rompe-se com o instituído e suas representações, instaurando possibilidades de produzir outros mundos e subjetividades. São movimentos e fluxos que impulsionam ações e pensamentos, os quais são engendrados nos cotidianos em suas múltiplas possibilidades.

Nossa aposta, é que a videoarte implica a mobilização na subjetividade do espectador, isto é, "de sua potência de vibrar as intensidades do mundo e de decifrar os signos formados por suas sensações. A obra promove no espectador uma espécie de "aprendizado dos signos" e, é exatamente com isso, que ela se completa" (ROLNIK, 2002, p. 7). Com isso, há um deslocamento no modo de subjetivação. Abre-se uma permeabilidade artística onde se instaura a possibilidade para transitar por uma experiência fora do sujeito nas dimensões do virtual. Rompem-se, assim, com a representação do mundo para virtualizá-lo.

\section{O virtual tecnológico}

Na nossa sociedade há uma cultura imagética baseada na representação. Contudo, as imagens de uma videoarte não devem ser compreendidas como a reprodução de um objeto. A tecnologia do vídeo permitiu outra relação com a imagem, mais precisamente, foram as novas tecnologias digitais de informação e comunicação que possibilitaram elas se tornarem virtuais, autônomas e autorreferentes (PARENTE, 1993). Neste sentido, com a imagem-vídeo foi possível superar a dicotomia existente entre imagem e o objeto.

Para Deleuze (1987) as imagens emitem signos. É aquilo que exerce sobre a subjetividade uma ação direta, sem a mediação da representação e que afetam o sujeito. Com efeito, nos tira do campo da recognição, quebrando e desmontando as formas constituídas socialmente - a forma de apreender a realidade por representação - e, com isso, cria embriões de outros mundos em estado virtual.

Experimentar o fora, por meio da videoarte, é experimentar a realidade de um virtual e sua atualização. No entanto, um ponto fundamental que precisa ser esclarecido é que a experiência do fora não se distingue do real. Em outras palavras, o fora é sempre real e constituído por virtualidades.

O virtual não se opõe ao real, mas somente ao atual. O virtual possui uma plena realidade enquanto virtual. Do virtual, é preciso dizer exatamente o que Proust dizia dos estados de ressonância: "reais sem serem atuais, ideais sem serem abstratos"; e simbólicos sem serem fictícios. $\mathrm{O}$ virtual deve até ser definido como uma estrita parte do objeto real como se o objeto tivesse uma das suas partes no virtual e nele mergulhasse como uma dimensão objetiva. (DELEUZE, 1988, p. 335)

O virtual, então, é concebido como uma esfera que coexistindo com o atual, entra em um estreito circuito com ele, e vice-versa. Virtual e atual não se separam, ao mesmo tempo que são distintos e indiscerníveis. Pode-se afirmar, na companhia de Deleuze, que eles se diferenciam. Explicamos melhor: quando o virtual se atualiza, é quando ele se diferencia. E o processo de atualização é a passagem do virtual ao atual. Podemos ir além, o "atual é o complemento, o produto, ou ainda o objeto de atualização, o virtual, por sua vez, é sujeito dessa atualização" (LEVY, 2011). 
A virtualização dissolve as esferas instituídas, desterritorializando identidades e desprendendo-as do tempo cronológico para deslizar pelo campo coletivo de forças. O virtual está relacionado com a criação. É fazer surgir o novo, ou ainda, de emergir outras formas de vida. Para Deleuze, "no virtual, a diferença e a repetição fundam o movimento da atualização, da diferenciação como criação, substituindo, assim, a identidade e a semelhança do possível, que só inspiram um pseudomovimento [...]" (1988, p. 342). Compreendemos, desse modo, que a criação de "uma vida" só ocorre pela diferenciação do virtual, de algo que ainda não têm forma.

Assim sendo, pelo fato das imagens de uma videoarte serem regidas sob o signo do inacabamento - uma obra-processo em que a plasticidade ganha lugar, características da vida, que pode ser um vetor especial de subjetivação, permitindo, também, inaugurar novas maneiras de pensar, as quais abalem o que nos é dado como certezas e verdades. Com isso, se introduz a possibilidade de produzir outras subjetividades e novos modos de existência.

\section{$O$ encontro da imagem-tempo com a videoarte}

O conceito de virtual em Deleuze está diretamente relacionado ao modo como concebe, também, o tempo. É por meio de um diálogo com Bergson que ele desenvolve sua concepção de tempo: diz ser a distinção entre o virtual e o atual o que marca a cisão mais fundamental do tempo (DELEUZE, 1988). Assim, compreende que a duração é uma invenção. E no seu livro Cinema II a imagem-tempo analisa o que seria um tempo não mais baseado na linearidade passado-presentefuturo. Ou seja, o tempo em seu estado original, um tempo do acontecimento, e não cronológico.

Nesse sentido, a questão central que envolve o cinema, segundo nosso filósofo, não se relaciona na existência de sequência narrativas, mas justamente na aparição do tempo na imagem. É sobretudo este aspecto que nos permite em aproximar a videoarte do conceito de imagem-tempo, já que sua principal característica se funda em implodir qualquer sequencialidade e linearidade narrativa.

As imagens cinematográficas podem ser classificadas, segundo Deleuze (1990), em dois tipos: imagens-movimento e imagens-tempo. A principal distinção entre os dois tipos de imagens é a sua relação com o tempo. Enquanto a primeira faz uma subordinação do tempo ao movimento, produzindo signos que representam a imagem-movimento, assim, o tempo é alcançado de forma indireta. Já a imagem-tempo realiza justamente o inverso: uma subordinação do movimento ao tempo. Ou seja, apresenta o tempo diretamente, sem fazer uma distinção linear entre presente, passado e futuro.

Será por meio de montagens descontínuas que tudo ocorre simultaneamente e o filme deixa de ser imagens em cadeia. O que se acredita é "numa força do fora que se escava, nos agarra e atrai o dentro. Já na acreditamos numa associação das imagens, nem mesmo transpondo vazios, acreditamos em cortes que adquirem valor absoluto e subordinam qualquer associação" (DELEUZE, 1990, p. 256).

Deleuze (1990) aprofunda o conceito de imagem-tempo pelo conceito de imagem-cristal. A imagem-cristal tem duas faces: atual e virtual, ou seja, é uma imagem atual-virtual. Isso quer dizer que "por oposição à imagem-movimento, a imagem-tempo é também virtual, ou, mais precisamente, é uma relação coalescente entre virtual e atual” (MACHADO, 2009, p. 276). Na medida em que a imagem não se prolonga mais em movimento, como no cinema clássico, abre a possibilidade dela se tornar uma unidade entre uma imagem atual e sua imagem virtual, do passado e do presente. E quando o virtual se atualiza, algo se cristaliza formando as imagens cristal.

O cristal revela uma imagem tempo direta, e não mais uma imagem indireta do tempo, que decorresse do movimento. Ele não abstrai o tempo, faz melhor, reverte sua subordinação em relação ao movimento. (...) O que o cristal revela 
ou faz ver é o fundamento oculto do tempo, quer dizer, sua diferenciação em dois jorros, o dos presentes que passam e o dos passados que se conservam. De uma só vez o tempo faz passar o presente e conserva em si o passado. Há, portanto, duas imagens-tempo possíveis, uma fundada no passado, outra no presente (DELEUZE, 1990, p. 121).

A imagem-cristal, dessa forma, não é o tempo, mas permite ver o tempo no cristal. Em outras palavras, vê-se a fundação do tempo, o tempo não cronológico, simultâneo, ontológico, o tempo em estado puro (MACHADO, 2009). O cristal retorna à subordinação do tempo ao movimento e revela uma imagem-tempo direta. No entanto, para que surja uma verdadeira imagem-tempo é preciso operar outro sistema diferente do sensório-motor, um que não seja da ação e reação imediata e das imagens clichês (idem). Estamos falando, portanto, do sistema sensório-tempo. Por fim, para Deleuze (1990), o cinema moderno é visto como criação de diferença. Podemos dizer, assim, que o cinema moderno e a videoarte, comunicam com o Fora.

\section{O território sensível de "Mannequin Death"}

É exatamente nessa interferência na cartografia vigente que a prática estética faz obra, sendo o bem sucedido da forma indissociável de seu efeito de problematização do mundo. $\mathrm{O}$ mundo liberta-se de um olhar que o reduz às suas formas constituídas e sua representação, para oferecer-se como matéria em processo de arranjo de novas composições e engendramento de novas formas. A arte participa da decifração dos signos das mutações sensíveis, inventando formas através das quais tais signos ganham visibilidade e integram-se ao mapa vigente. A arte é, portanto, uma prática de experimentação que participa da transformação do mundo (ROLNIK, 2002, p. 45-46).

A videoarte Mannequin Death ${ }^{3}$ - traduzido por "Morte do Manequim" - de John Miller e Richard Hoeck cumpre esse papel da arte na medida em que coloca a subjetividade em obra (ROLNIK, 2002) e aproxima a arte da vida. As imagens são hipnotizantes e perturbadoras que vão além das representações. Parados precariamente em uma bucólica encosta alpina, uma série de manequins despencam sobre a borda de um penhasco em uma pedreira, um a um. O agressor, aparentemente, é um braço de

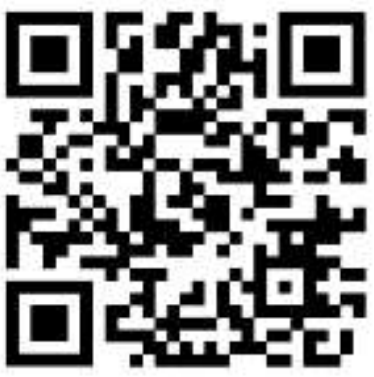
manequim que surge abruptamente.

Embora as vítimas sejam inconfundivelmente manequins, a imagem delas batendo nas rochas, com seus membros de plástico desalojando em sua descida, permanece irremediavelmente violenta. Miller e Hoeck (2016) provocam essa reação por meio do estilo meticuloso dos manequins que usam adereços, vestimentas e calçados que como aqueles encontrados em boutiques de shoppings, nos capturam e modelam nossa subjetividade.

A situação referenciada pode associar-se aos espectadores das vitrines de lojas, dos panfletos, das mídias comerciais e das redes sociais como se fossem consumidores/as de subjetividades, isto é, consomem sistemas de representação. Semelhantemente, Guattari e Rolnik (1986) fazem uma analogia usando a linguagem da informática em que o indivíduo existe enquanto terminal. Quer dizer, um terminal individual que se encontra na posição de consumidor de subjetividades.

\footnotetext{
${ }^{3}$ Disponibilizamos um QR code para o leitor assistir ao videoarte.
} 
Em um depoimento para uma galeria de arte que expôs seu vídeo, Miller (2016) comparou as figuras solitárias dos manequins com aquelas situadas entre as grandiosas paisagens do pintor romântico alemão Caspar David Friedrich. Como os personagens de Friedrich, Miller (2016) afirmou que esses manequins constituem "posições de sujeitos vazios", agindo como substitutos para o espectador. Destacamos que essa é uma das possíveis situações que corroboram a perspectiva apontada por Guattari e Rolnik (1986) ao denominarem de subjetividade de natureza industrial - maquínica - aquela que é essencialmente fabricada, modelada, recebida e consumida pelo sujeito de forma passiva.

Os indivíduos, no entanto, podem viver a subjetividade numa relação de alienação e opressão, na qual se submetem à subjetividade da forma como a recebem (GUATTARI; ROLNIK, 1986). Por outro lado, é possível viver a subjetividade numa relação de expressão e criação, na qual o indivíduo se reapropria dos componentes da subjetividade, produzindo o que Guattari e Rolnik (1986) chamam de singularização. O que caracteriza para esses autores um processo de singularização é que os sujeitos construam seus próprios tipos de referências para que não fiquem

[...] na posição constante de dependência, em relação ao poder global, em nível econômico, em nível de saber, em nível técnico, em nível das segregações, dos tipos de prestígios que são difundidos. A partir do momento em que os grupos adquirem essa liberdade de viver seus processos, eles passam a ter uma capacidade de ler sua própria situação e aquilo que se passam em torno deles (GUATTARI; ROLNIK, 1986, p. 55).

Diante disso, precisamos questionar essa política do desejo em que reduz a subjetividade a uma constante dependência em relação a modelos totalizantes e homogeneizantes. O que se faz necessário é restabelecer um tipo de existência que tenha a vida como potência de diferenciação e invenção, uma micropolítica ativa do desejo (ROLNIK, 2018). Nessa micropolítica, as ações do desejo, para a autora, consistem em atos de criação que se inscrevem nos territórios existenciais estabelecidos e suas respectivas cartografias.

\section{Apontamentos conclusivos}

Conforme discutimos ao longo do artigo, o advento das tecnologias digitais permitiu alcançar a produção de uma imagem que não busca representações e que consegue estimular outros sentidos para além da visão humana. A imagem-vídeo nos dá acesso ao mundo do campo coletivo de forças (em devir) ao invés de formas e representações. Nos promove uma experiência do fora que possibilita o surgimento de uma nova maneira de nos relacionar com a realidade, abrindo outras possibilidades de vida e de mundos.

Quando a videoarte trabalha com uma estética da incompletude, deixando questões em aberto, perguntas sem respostas e sem a pretensão de explicar algo ou contar uma história, possibilita um outro agenciamento com o espectador. O que existe são múltiplas produções de sentidos e linguagens sem pretensão de estabelecer padrões de compreensão, diante das tantas possibilidades de significação. A imagem-vídeo só pode ser entendida enquanto processo e que opera num regime sensório-temporal - marcado pelo tempo.

Ao final, analisamos, também, os territórios sensíveis da videoarte Mannequim Death, buscando ressonância entre a filosofia de Félix Guattari e Suely Rolnik, com os conceitos de subjetividade maquínica e singularização. Refletimos como as imagens deste vídeo podem provocar composições coletivas e intensivas nos sujeitos, de modo que se reinventem e ressignifiquem suas visões de mundo. 


\section{Referências}

COHN, Greice. A videoarte e a pedagogia do deslocamento. In: ENCONTRO DA ASSOCIAÇÃO NACIONAL DE PESQUISADORES EM ARTES PLÁSTICAS, 26., 2017, Campinas. Anais... Campinas: Pontifícia Universidade Católica de Campinas, 2017. p. 1701-1716.

DELEUZE, Gilles. Proust e os signos. Rio de Janeiro: Forense Universitária, 1987.

DELEUZE, Gilles. Diferença e repetição. Tradução de Luiz Orlandi e Roberto Machado. Rio de Janeiro: Graal, 1988.

DELEUZE, Gilles. A imagem-tempo. São Paulo: Brasiliense, 1990.

GUATTARI, Félix; ROLNIK, Suely. Micropolítica: cartografias do desejo. Rio de Janeiro: Vozes, 1986.

LEVY, Tatiana Salem. A experiência do fora: Blanchot, Foucault e Deleuze. Rio de Janeiro: Civilização Brasileira, 2011.

MACHADO, Roberto. Deleuze, a arte e a filosofia. Rio de Janeiro: Zahar, 2009.

MILLER, John; HOECK, Richard. A morte do manequim. Nova York, 3min14s, 2016. Disponível em: https://vimeo.com/195890880.

MILLER, John. John Miller \& Richard Hoeck: mannequin death viewings. 2016. Disponível em: https://www.marcjancou.com/news/john-miller-richard-hoeck-mannequin-death-viewings.

Acesso em: 28 de setembro de 2020.

PARENTE, André. Imagem-máquina: a era das tecnologias do virtual. Rio de Janeiro: Ed. 34, 1993.

ROLNIK, Suely. Subjetividade em obra: Lygia Clark, artista contemporânea. Projeto História, São Paulo, v. 25, p. 43-54, 2002.

ROLNIK, Suely. Esferas da insurreição: notas para uma vida não cafetinada. São Paulo: n-1 edições, 2018.

\section{Sobre os autores}

Hugo Souza Garcia Ramos. Pedagogo. Mestre em Psicologia Institucional e Doutorando em Educação pela Universidade Federal do Espírito Santo - UFES. Bolsista CAPES.

E-mail: hugo-sgramos@ hotmail.com.

Geide Rosa Coelho. Graduado em Física Licenciatura pela Universidade Federal de Minas Gerais (2001), Mestre em Educação pela Universidade Federal de Minas Gerais (2007) e Doutor em Educação pela Universidade Federal de Minas Gerais (2011). Atualmente é professor da área de ensino de Física no Centro de Educação da Universidade Federal do 
Espírito Santo (2010) atuando no curso presencial e na modalidade a distância e professor dos Programas de Pós-Graduação em Educação e Ensino de Física (PPGEnFis) da UFES.

E-mail: geidecoelho@gmail.com. 